\title{
Mechanical properties of zirconia-titanium composites
}

\author{
Hideaki Tsukamoto \\ Graduate School of Engineering, Nagoya Institute of Technology, Nagoya, Japan
}

\section{Email address:}

tsukamoto.hideaki@nitech ac.jp

\section{To cite this article:}

Hideaki Tsukamoto. Mechanical Properties of Zirconia-Titanium Composites. International Journal of Materials Science and Applications. Vol. 3, No. 5, 2014, pp. 260-267. doi: 10.11648/j.ijmsa.20140305.28

\begin{abstract}
This study aims to investigate mechanical properties of $\mathrm{ZrO}_{2}$-Ti composites. The samples have been fabricated by spark plasma sintering (SPS). The experimental results demonstrate that a small amount of $\mathrm{ZrO}_{2}$ can enhance Ti matrix in hardness and tensile strength, while a large amount of $\mathrm{ZrO}_{2}$ degrade the tensile strength and ductility because of high extent of formation of titanium oxide. The mechanical properties of $\mathrm{ZrO}_{2}$-Ti composites can be related to thermo-mechanical behavior of $\mathrm{ZrO}_{2}$ /Ti functionally graded materials (FGMs). In the FGMs, titanium oxide has also formed, which can largely influence thermo-mechanical behavior of the FGMs.
\end{abstract}

Keywords: $\mathrm{ZrO}_{2}$-Ti Composites, Titanium Oxide, Functionally Graded Materials (FGMs), Spark Plasma Sintering (SPS)

\section{Introduction}

$\mathrm{ZrO}_{2}$-Ti composites including $\mathrm{ZrO}_{2} / \mathrm{Ti}$ functionally graded materials (FGMs) are attractive in totally different fields of both bio-medical and aerospace industries. Because of good biocompatibility of Ti due to its non-toxicity and non-rejection to the human body, Ti has been of considerable interest in medical fields, which can be used for surgical implements and implants. $\mathrm{ZrO}_{2}$-dispersed $\mathrm{Ti}$ matrix composites have been of remarkable use in biomedical fields [1]. Besides this, $\mathrm{ZrO}_{2}$-dispersed Ti matrix composites have been also expected to be high-temperature materials in aerospace and automobile industries. $\mathrm{ZrO}_{2}$ has superior thermal and mechanical properties, which are effective as thermal barrier functions [2]. One of superior mechanical properties of $\mathrm{ZrO}_{2}$ is high fracture toughness due to stress-induced transformation (from tetragonal to monoclinic crystal structures under stress conditions), which can be used in enhancement of fracture toughness of other ceramics and ceramics matrix composites [3-6]. Mechanical properties of $\mathrm{ZrO}_{2}$-Ti composites have been of interest in many industries.

In the past decade, $\mathrm{ZrO}_{2}$-Ti composites have been of high potential for applications to high temperature structures including thermal barrier coatings (TBCs) in aerospace and automobile industries. Particularly the functionally graded (FG) structures of $\mathrm{ZrO}_{2}$-Ti systems is potential as super high-temperature TBCs. The FGMs are advanced multi-phase composites that are engineered to have a smooth spatial variation of material constituents. The advantages of FGMs as an alternative to two dissimilar materials (ceramics and metal) joined directly together include smoothing of thermal stress distributions across the layers, minimization or elimination of stress concentrations and singularities at the interface corners and increase in bonding strength [6-9].

Several studies have been conducted investigating the phase transformation of $\mathrm{ZrO}_{2}$ caused by thermal stresses generated in FGMs $[10,11]$. Teng et al [11] showed that only $\alpha$-Ti, tetragonal $\mathrm{t}-\mathrm{ZrO}_{2}$, and monoclinic $\mathrm{m}-\mathrm{ZrO}_{2}$ were found in various $\mathrm{Ti}-\mathrm{ZrO}_{2}$ composites after annealing from 1400 to $1650{ }^{\circ} \mathrm{C}$. It was reported that the volume fraction of $\mathrm{m}-\mathrm{ZrO}_{2}$ increased with $\mathrm{Ti}$ content in the $\mathrm{Ti}-\mathrm{ZrO}_{2}$ composites, while the interfacial stresses, arising from the plastic deformation of $\mathrm{Ti}$ and the thermal expansion mismatch of $\mathrm{Ti}$ and $\mathrm{ZrO}_{2}$, were the driving forces for the phase transformation from $\mathrm{t}-\mathrm{ZrO}_{2}$ to $\mathrm{m}-\mathrm{ZrO}_{2}$. The interfacial reaction between $\mathrm{Ti}$ and $\mathrm{ZrO}_{2}$ in FGMs has been also studied so far [12]. Thermodynamic analysis is essential for chemical design of $\mathrm{Ti}-\mathrm{ZrO}_{2}$ composites [11, 12]. It was reported that the standard Gibbs free energy of $\mathrm{Ti}_{2} \mathrm{O}$ plays an important role in the thermodynamic assessment of $\mathrm{Ti}-\mathrm{ZrO}_{2}$ system, in which the formation of $\mathrm{Ti}_{2} \mathrm{O}$ is easier than that of the other titanium oxides [13]. It was reported by Lin and Lin [12] that in $\mathrm{ZrO}_{2} / \mathrm{Ti}$ FGMs the microstructures and reaction products of $\mathrm{Ti}$ and $\mathrm{ZrO}_{2}$ depends on $\mathrm{Ti} / \mathrm{ZrO}_{2}$ ratios.

It is well known that mechanical properties of $\mathrm{ZrO}_{2}$ can be enhanced by incorporating Ti. Weber et al. [14] reported that 
sintered $\mathrm{ZrO}_{2}$ crucibles containing 15 at $\%$ Ti showed superior strength and thermal shock resistance. Arias [15] also found that the thermal shock resistance and strength of $\mathrm{ZrO}_{2}$ with $15 \mathrm{~mol} \%$ Ti were increased due to the inhabitance of grain growth of $\mathrm{ZrO}_{2}$ by Ti during the sintering at $1850{ }^{\circ} \mathrm{C}$. In their research, they considered that these phenomenon were related to dissolution of oxygen atom into Ti to form titanium oxides without taking into account possible reactions between $\mathrm{Ti}$ and $\mathrm{ZrO}_{2}$.

Spark plasma sintering (SPS) is characterized by an electric source of direct pulsed current, which is similar to that of an electric discharge machine. The direct pulsed current of SPS can be continuously applied from start to finish of the process. SPS is advantageous for sintering of metals and ceramics, and has been also used for consolidation of metallic glass powder, chemical reaction in organic compounds, crystal growth of materials such as $\mathrm{CoSb}_{3}$, joining of steel, fabrication of $\mathrm{Al}$ alloy with fine crystal, facilitation of FGMs [16].

In this study, mechanical properties of micro-Vickers hardness and tensile behaviour of $\mathrm{ZrO}_{2}-\mathrm{Ti}$ composites fabricated by SPS have been investigated. The effects of amount of $\mathrm{ZrO}_{2}$ in $\mathrm{Ti}$ matrix on the mechanical properties have been examined systematically to effectively design such kinds of the composites. The results can be also of considerable use to understand thermo-mechanical behaviour of $\mathrm{ZrO}_{2} / \mathrm{Ti}$ FGMs based on a mean-field micromechanics-based model [7].

\section{Experimental Procedures}

\subsection{Fabrication}

The prepared powders were $\mathrm{Ti}$ powder with the average diameter of $45 \mu \mathrm{m}$ and $\mathrm{ZrO}_{2}$ stabilized by $3 \mathrm{~mol} \% \mathrm{Y}_{2} \mathrm{O}_{3}$ and $0 \mathrm{~mol} \% \mathrm{Y}_{2} \mathrm{O}_{3}$ with the average diameter of $26 \mathrm{~nm}$. The SPS was conducted in vacuum at $1400{ }^{\circ} \mathrm{C}$ under the uniaxial pressure of $30 \mathrm{MPa}$ with the time duration of 20 minutes. The sintered samples have a diameter of $20 \mathrm{~mm}$ and a thickness of $9 \mathrm{~mm}$ for $\mathrm{ZrO}_{2}-\mathrm{Ti}$ composites and the FGMs. The composites, in which $\mathrm{ZrO}_{2}\left(3 \mathrm{~mol} \% \mathrm{Y}_{2} \mathrm{O}_{3}\right)$ particles are distributed uniformly, contain $\mathrm{ZrO}_{2}$ stabilized by 3 mol \% $\mathrm{Y}_{2} \mathrm{O}_{3}$, whose volume fraction ranges from 0 to $30 \%$. The FGM sample has the FGM part with a $3 \mathrm{~mm}$ thickness and Ti substrate part with a $6 \mathrm{~mm}$ thickness. The FGM part consists of 6 layers with different compositions such as $0,20,40,60$, 80 and 100 vol\% of $\mathrm{ZrO}_{2}$ with an equal thickness $(0.5 \mathrm{~mm})$ for each layer resulting in such a linear step-wised compositional gradient pattern. For the FGMs, two kinds of powders of $\mathrm{ZrO}_{2}$ stabilized with $3 \mathrm{~mol} \% \mathrm{Y}_{2} \mathrm{O}_{3}$ and $0 \mathrm{~mol} \%$ $\mathrm{Y}_{2} \mathrm{O}_{3}$ were used. The FGMs were also sintered under the above conditions using SPS.

\subsection{Characterization}

A microstructure observation was conducted using optical microscope (OM) and scanning electron microscope (SEM, JSM-5900LV, JEOL, Japan) with an acceleration voltage of $15 \mathrm{kV}$. The composition in the samples was identified using the SEM energy-dispersive X-ray spectroscopy (EDS, JED-2200). The microscope samples were prepared by embedding into the resin.

The XRD investigation was performed with $\mathrm{Cu}$ $\mathrm{K} \alpha$ radiation using the Rigaku XRD meter. The $2 \theta$ was measured from $10^{\circ}$ to $90^{\circ}$ in steps of $0.02^{\circ}$ with a scan speed of $2 \% \mathrm{~min}$.

Micro-Vickers hardness tests were conducted with Shimazdu Micro-Vickers Tester. Nanoindentation tests were performed with a U9820A Agilent nano indenter G200 (Agilent Tech. Inc., USA), whose resolutions of the loading and displacement of the systems are $50 \mathrm{nN}$ and less than $0.01 \mathrm{~nm}$, respectively. A Berkovich diamond indenter was used. The thermal drift rate was less than $1 \mathrm{~nm} / \mathrm{s}$. A strain rate was set at $0.05 / \mathrm{s}$. All the tests were conducted at room temperature (R.T.). Tensile tests were conducted with an Instron-type machine with the strain rate of $10^{-5} / \mathrm{sec}$. The tensile specimen with the dimensions is shown in Fig. 1. The specimen was cut from the sintered composite samples. The strain was measured using strain gages attached to both sides of the tensile specimens.

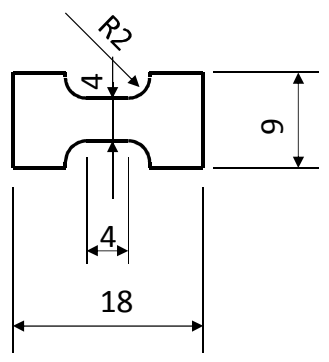

Figure 1. Tensile test specimen for Ti-ZrO $\mathrm{O}_{2}$ composites fabricate by SPS.

\section{Experimental and Simulation Results}
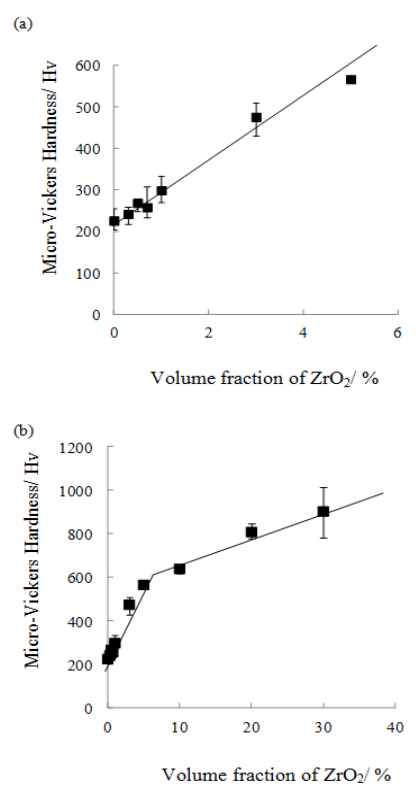

Figure 2. Micro Vickers hardness of Ti-ZrO2 composites (a)Range of volume of $\mathrm{ZrO} 2$ is 0 to $1 \%$ (b)Range of volume of $\mathrm{ZrO} 2$ is 0 to $30 \%$. 
The fabricated $\mathrm{ZrO}_{2}$-Ti composites were investigated on hardness and tensile behavior. Fig. 2 shows Micro Vickers hardness of $\mathrm{ZrO}_{2}$-Ti composites. It is seen that small amount (less than 5 vol. \%) of $\mathrm{ZrO}_{2}$ can increase hardness of $\mathrm{Ti}$ matrix drastically. In the range of higher than 10 vol. $\%$ of $\mathrm{ZrO}_{2}$, hardness of $\mathrm{ZrO}_{2}-\mathrm{Ti}$ composites increases more gradually with increasing volume fraction of $\mathrm{ZrO}_{2}$ compared to less than 5 vol. $\%$ of $\mathrm{ZrO}_{2}$. Much attention will be paid to the composites with small amount of $\mathrm{ZrO}_{2}$ reinforced Ti composites because of high effectiveness of $\mathrm{ZrO}_{2}$ addition into $\mathrm{Ti}$ in enhancement of mechanical properties such as hardness of $\mathrm{Ti}$.

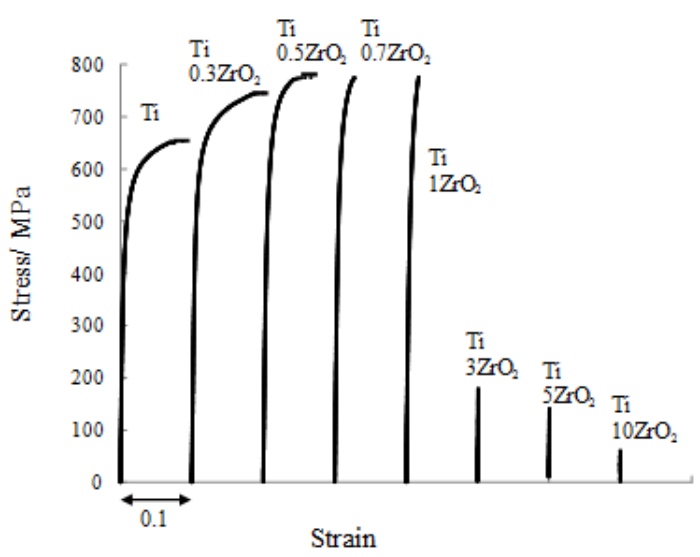

Figure 3. Tensile stress-strain curves of $\mathrm{Ti}_{\mathrm{i}} \mathrm{ZrO} \mathrm{O}_{2}$ composites.

(a)

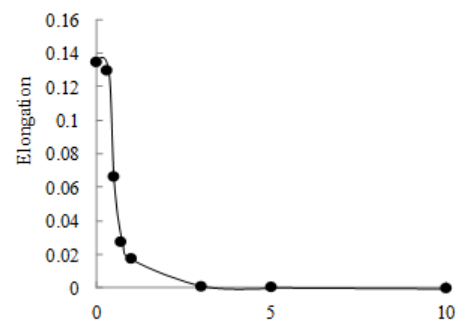

(b)

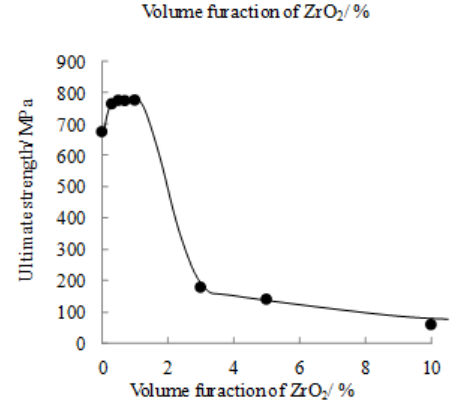

(c)

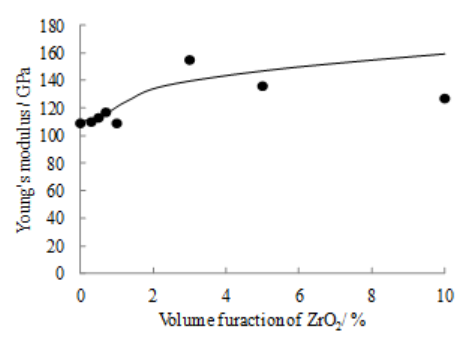

Figure 4. Features in tensile behavior of $\mathrm{Ti}-\mathrm{ZrO}_{2}$ composites Ultimate tensile strength Elongation at failure (c) Young's modulus.
Next let us look at tensile behavior of $\mathrm{ZrO}_{2}$-Ti composites. Fig. 3 shows the tensile stress-strain curves of the composites. It is seen that up to 1 vol. $\%$ of $\mathrm{ZrO}_{2}$ content, tensile strength increases with increasing volume fraction of $\mathrm{ZrO}_{2}$, while the elongation of the composites decrease drastically at higher content of $\mathrm{ZrO}_{2}$ than 1 vol. \%. Now the data has been summarized in Fig. 4. It is seen that even 0.2 vol $\% \mathrm{ZrO}_{2}$ decrease elongation by a half, which implies that fracture toughness and ductility of the composites drastically decreases with increasing $\mathrm{ZrO}_{2}$ content. It is inevitable to have high caution to reduction of ductility due to $\mathrm{ZrO}_{2}$ addition in $\mathrm{Ti}$ matrix in design of such composites. According to the work by $\mathrm{Lin}$ and $\mathrm{Lin}$ [12], $\mathrm{ZrO}_{2}$ reacts with $\mathrm{Ti}$ to form $\mathrm{Ti}$ oxide, which obviously makes $\mathrm{ZrO}_{2}-\mathrm{Ti}$ composites brittle. Young's modulus of the composites slightly increases with increasing $\mathrm{ZrO}_{2}$ content.

Fig. 5 shows SEM images (low and high magnifications) and EDS analysis data of $\mathrm{ZrO}_{2}$-Ti composites with 10, 20 and 30 vol. $\%$ of $\mathrm{ZrO}_{2}$. It is seen in Fig. 5 (a) that $\mathrm{ZrO}_{2}$ seems to disperse uniformly in $\mathrm{Ti}$ matrix because there is no gathering of $\mathrm{ZrO}_{2}$ particles, which is supported by EDS analysis data showing constant ratios of elements anywhere in the image. From SEM images and EDS data in Fig. 5 (b) and (c), there is some lack of uniformity in $\mathrm{Zr}$, Ti and $\mathrm{O}$ distributions and it is considered that Ti-Zr-O compounds exist in the composites, which may cause reduction of ductility and increase of brittleness of the composites.

(a)

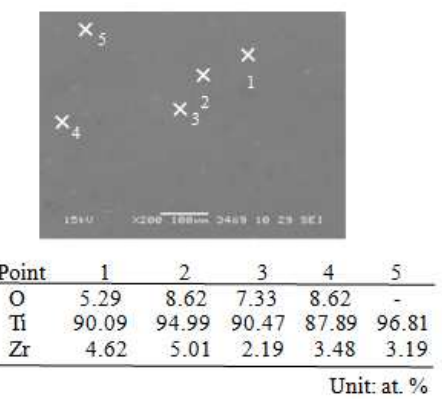

(b)
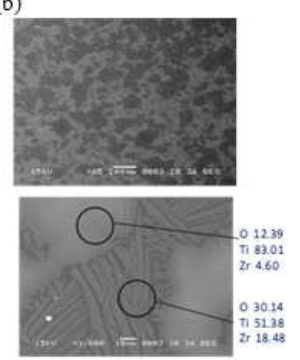

Unit: at. \% (c)
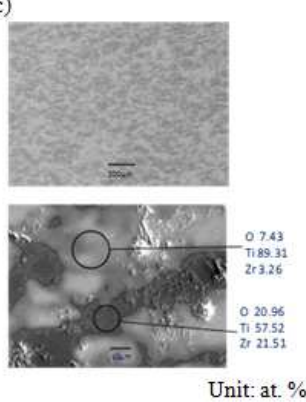

Figure 5. SEM images and EDS analysis data for Ti-ZrO $\mathrm{O}_{2}$ composites (a) Ti-10 vol. \% $\mathrm{ZrO}_{2}$ composites(b) Ti-20 vol. \% $\mathrm{ZrO}_{2}$ composites (c) Ti-30 vol. $\% \mathrm{ZrO}_{2}$ composites

So far we have been looking at mechanical properties of $\mathrm{ZrO}_{2}-\mathrm{Ti}$ composites, in which $\mathrm{ZrO}_{2}$ are distributed uniformly in Ti matrix. Next let us examine $\mathrm{ZrO}_{2} / \mathrm{Ti}$ FGMs. 
Fig. 6 shows schematic illustration of an $\mathrm{ZrO}_{2}(3 \mathrm{~mol} \%$ $\mathrm{Y}_{2} \mathrm{O}_{3}$ ) /Ti FGM sample with an OM image and an SEM image with EDS analysis data providing element ( $\mathrm{Zr}$, Ti and O) distributions. It can be seen that the $\mathrm{ZrO}_{2}\left(3 \mathrm{~mol} \% \mathrm{Y}_{2} \mathrm{O}_{3}\right)$ /Ti FGM samples were successfully fabricated without any defects and cracks. FGM parts have step-wised linear gradation patterns, but diffusion during fabricating process made compositional gradation smoother. Based on the EDS examination, $\mathrm{Zr}$ and $\mathrm{Ti}$ vary gradually from one side to another side, while $\mathrm{O}$ is distributed relatively uniformly in the FGM part, which means that Ti possibly makes an oxidation with $\mathrm{O}$ coming from $\mathrm{ZrO}_{2}[11,12]$.

(a)
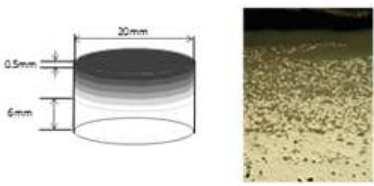

(b)

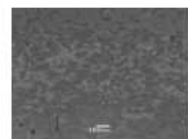

(d)

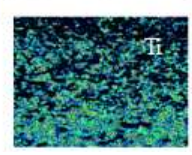

(c)
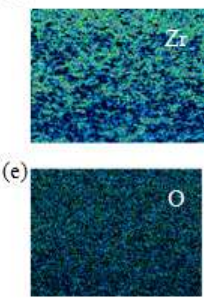

Figure 6. Sample illustration and $\mathrm{OM}$ image of $\mathrm{ZrO}_{2}\left(3\right.$ vol. $\left.\mathrm{Y}_{2} \mathrm{O}_{3}\right) / \mathrm{Ti}$ FGMs and SEM image with EDS data of compositional distributions. (a)Sample illustration and $\mathrm{OM}$ image of $\mathrm{ZrO}_{2}\left(3\right.$ vol. $\left.\mathrm{Y}_{2} \mathrm{O}_{3}\right) / \mathrm{Ti}$ FGMs (b)SEM image (c)EDS map for distribution of $\mathrm{Zr}$ (d) EDS map for distribution of Ti (e)EDS map for distribution of $O$.

Nanoindentation elastic modulus and hardness of $\mathrm{ZrO}_{2}(3$ mol $\left.\% \mathrm{Y}_{2} \mathrm{O}_{3}\right) \quad / \mathrm{Ti}$ FGMs are shown in Fig. 8. Nanoindentation indenter is very small compared to micro-Vickers one, which make it possible to probe elastic modulus and hardness of each constituent phase such as $\mathrm{Ti}$ or $\mathrm{ZrO}_{2}$. It is seen that hardness and elastic modulus of Ti in the FGM part is as high as those of $\mathrm{ZrO}_{2}$. Hardness and elastic modulus of $\mathrm{Ti}$ in the substrate far from the FGM part are much lower than those of $\mathrm{Ti}$ in the FGM part. These may be attributed to presence of titanium oxide in Ti phase in the FGM part.

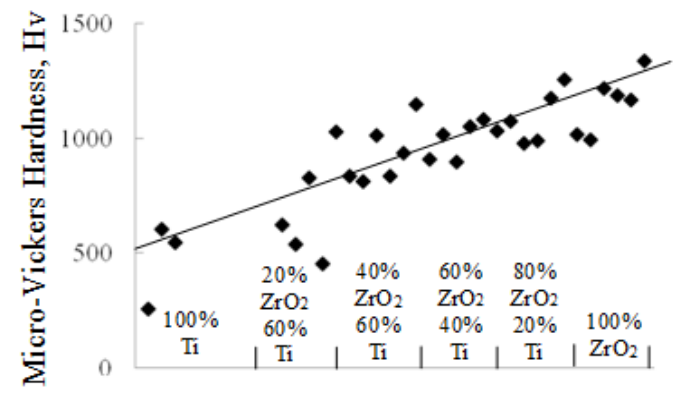

Position $/ \mu \mathrm{m}$

Figure 7. MicroVickers hardness distribution in $\mathrm{ZrO}_{2}\left(3 \mathrm{~mol} \% \mathrm{Y}_{2} \mathrm{O}_{3}\right) / \mathrm{Ti}$ FGMs.

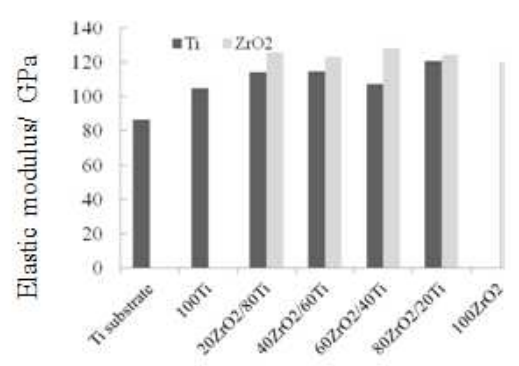

(b)

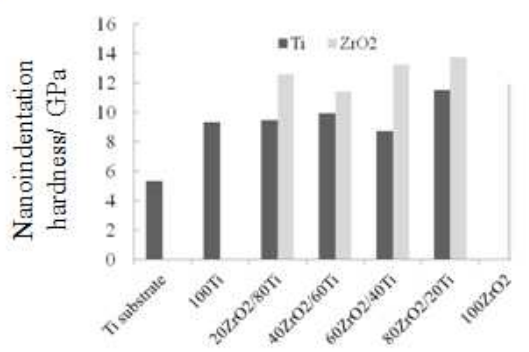

Figure 8. Nanoindentation elastic modulus and hardness of $\mathrm{ZrO}_{2} / \mathrm{Ti}$ FGMs. (a) Elastic modulus (b) Hardness.

Fig. 9 shows X-ray diffraction pattern for the $\mathrm{ZrO}_{2}$ surface layer in $\mathrm{ZrO}_{2}\left(3 \mathrm{~mol} \% \mathrm{Y}_{2} \mathrm{O}_{3}\right) / \mathrm{Ti}$ FGMs. It is seen that the peaks for tetragonal crystal structure appears clearly and a small peak for monoclinic crystal structure could be detected.

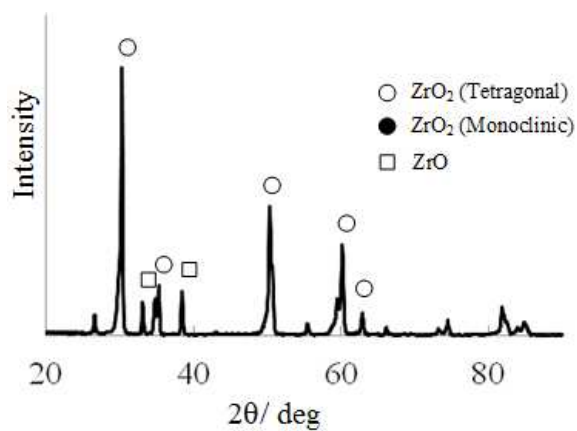

Figure 9. X-ray diffraction pattern of $\mathrm{ZrO}_{2}$ surface in the FGM part.

Next we examine the stress states just after SPS fabrication based on a mean-field micromechanics-based analysis. Brief description of the mean-filed micromechanics model used in the current study is given in Appendix. The detail of the model is shown in the work by Tsukamoto [7]. Thermo-mechanical boundary conditions the FGM experience during the fabrication processes and the material property data of both $\mathrm{Ti}$ and $\mathrm{ZrO}_{2}$ used in the calculation are also described in Appendix. Fig. 10 shows the simulation results for in-plane and out-of plane stresses in $\mathrm{ZrO}_{2}$ phase and $\mathrm{Ti}$ phase in the FGMs. It is seen that in-plane stresses in $\mathrm{ZrO}_{2}$ phase in the FGMs are tensile, while out-of-plane stresses $\mathrm{n} \mathrm{ZrO}_{2}$ phase in the FGMs are compressive. It is seen that both in-plane and out-of-plane stresses in $\mathrm{Ti}$ phase in the FGMs are tensile, in which in-plane tensile stresses are higher than out-of-plane stresses. Such in-plane stresses may cause crack generations and 
propagations in $\mathrm{Ti}$ phase containing titanium oxides in the FGMs.

(a)

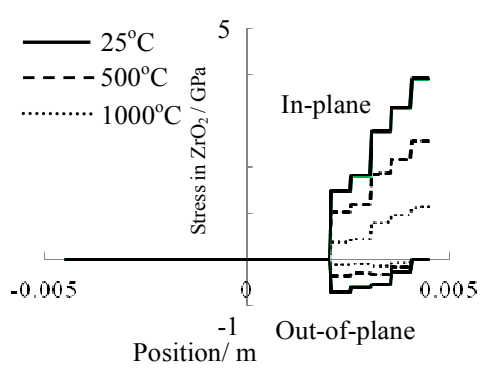

(b)

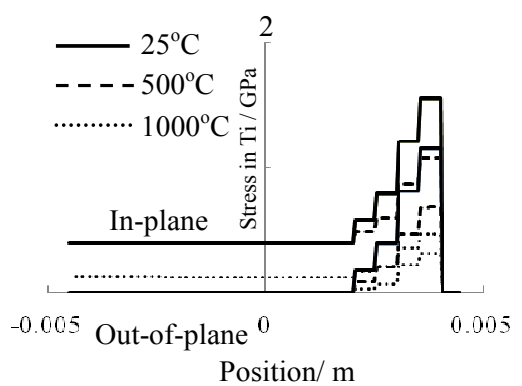

Figure 10. Micro-stresses in $\mathrm{ZrO}_{2}$ phase and Ti phase in the FGMs. (a) Micro stress in $\mathrm{ZrO}_{2}$ phase (b)Micro stress in Ti phase.

(a)

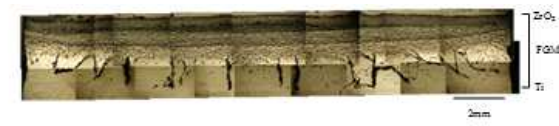

(b)

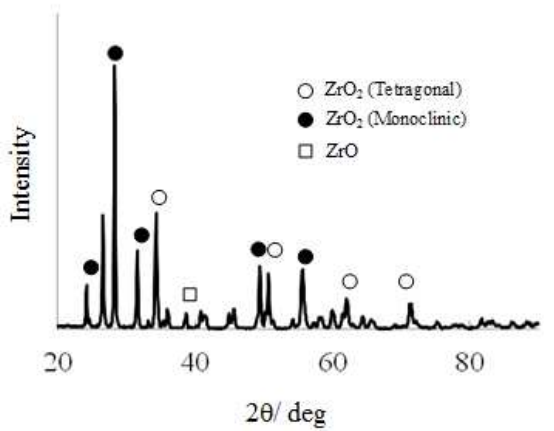

Figure 11. OM image of $\mathrm{ZrO}_{2}\left(0 \mathrm{~mol} \% \mathrm{Y}_{2} \mathrm{O}_{3}\right) / \mathrm{Ti}$ FGMs and X-ray diffraction pattern of $\mathrm{ZrO}_{2}$ surface. (a)OM image (b)X-ray diffraction pattern.

Fig. 11 shows $\mathrm{OM}$ image of microstructure and XRD pattern for $\mathrm{ZrO}_{2}$ surface layer in $\mathrm{ZrO}_{2}\left(0 \mathrm{~mol} \% \mathrm{Y}_{2} \mathrm{O}_{3}\right) / \mathrm{Ti}$ FGMs. The distinctive feature of microstructure of $\mathrm{ZrO}_{2}(0$ mol\% $\left.\mathrm{Y}_{2} \mathrm{O}_{3}\right) /$ Ti FGMs includes the fact that there are a lot of cracks around the $20 \% \mathrm{ZrO}_{2} / 80 \% \mathrm{Ti}$ and $100 \% \mathrm{Ti}$ layers in $\mathrm{ZrO}_{2}\left(0 \mathrm{~mol} \% \mathrm{Y}_{2} \mathrm{O}_{3}\right) / \mathrm{Ti}$ FGM samples. All these cracks are perpendicular to the $\mathrm{ZrO}_{2}$ surface, existing around $\mathrm{Ti}$ layer in the FGM part. It is expected that in-plane residual stresses in the $\mathrm{Ti}$ (containing titanium oxides) layer cause such crack generations and propagations in $\mathrm{ZrO}_{2}\left(0 \mathrm{~mol} \% \mathrm{Y}_{2} \mathrm{O}_{3}\right) / \mathrm{Ti}$ FGMs, in which toughening by stress-induced transformation of $\mathrm{ZrO}_{2}$ is considered to hardly occur in $\mathrm{ZrO}_{2}$ $\left(0 \mathrm{~mol} \% \mathrm{Y}_{2} \mathrm{O}_{3}\right)$ because most of $\mathrm{ZrO}_{2}\left(0 \mathrm{~mol} \% \mathrm{Y}_{2} \mathrm{O}_{3}\right)$ were already transformed from tetragonal to monoclinic structures during the fabrication process as seen in the XRD pattern in Fig. 11 (b). The volume expansion due to the $\mathrm{ZrO}_{2}$ transformation during the cooling processes in fabrication also causes large stresses in the materials, which leads to breakage of such FGMs.

\section{Discussion}

$\mathrm{ZrO}_{2}-\mathrm{Ti}$ composites are promising materials in bio-medical, aerospace as well as automobile industries. In $\mathrm{ZrO}_{2}$-Ti composites, behavior of atom of oxygen is a key factor to understand mechanical properties of the composites In the fabrication process, some of oxygen atoms are considered to react with $\mathrm{Ti}$, and form titanium oxide, which may contribute to enhancement of hardness of Ti phase [17]. Mechanical properties of $\mathrm{ZrO}_{2}$-Ti composites are highly affected by formation of titanium oxide in $\mathrm{Ti}$ matrix. However, XRD data with 1 vol.\% $\mathrm{ZrO}_{2}$ dispersed Ti matrix composites could not show any peak for titanium oxide as described in the previous work by Tsukamoto et al. [17]. Hardness drastically increases with increasing $\mathrm{ZrO}_{2}$ content up to 1 vol. $\%$ of $\mathrm{ZrO}_{2}$, which make consider that the compression strength of the composites may increase in the similar way to hardness. Even very small amount of $\mathrm{ZrO}_{2}$ contribute to forming Ti oxide, which leads to enhancement of hardness as well as brittleness of the composites as shown in Fig. 4.

For $\mathrm{ZrO}_{2} / \mathrm{Ti}$ FGMs Ti phase in the FGM part showed high nanoindentation hardness and elastic modulus as seen in Fig.8. It is considered that small amount of $\mathrm{ZrO}_{2}$ can increase hardness of $\mathrm{Ti}$ in the FGMs as well because of formation of titanium oxides, in which $\mathrm{O}$ may come from $\mathrm{ZrO}_{2}$. According to the work by Lin and Lin [12], Ti reacted with and was mutually soluble in $\mathrm{ZrO}_{2}$, resulting in the formation of a-Ti(O, $\mathrm{Zr}), \mathrm{Ti}_{2} \mathrm{ZrO}$, and/or $\mathrm{TiO}$. These oxygen containing phases extracted oxygen ions from $\mathrm{ZrO}_{2}$, whereby oxygen-deficient $\mathrm{ZrO}_{2}$ was generated. For relatively small Ti/ $\mathrm{ZrO}_{2}$ ratios, less than $30 \mathrm{~mol} \% \mathrm{Ti}$, TiO were formed, and for $50 \mathrm{~mol} \% \mathrm{Ti}$, lamellar type of $\mathrm{Ti}_{2} \mathrm{ZrO}$ precipitated in a- $\mathrm{Ti}(\mathrm{Zr}, \mathrm{O})$ without $\mathrm{TiO}$. In the present study on $\mathrm{ZrO}_{2}-\mathrm{Ti}$ composites, some zirconium-titanium-oxide and $\alpha-\mathrm{Ti}(\mathrm{Zr}, \mathrm{O})$ can form in the composites.

In case of $\mathrm{ZrO}_{2}\left(0 \mathrm{~mol} \% \mathrm{Y}_{2} \mathrm{O}_{3}\right) / \mathrm{Ti}$ FGMs, a lot of large cracks perpendicular to the surface can be observed as seen in Fig. 11 (a), which can be caused by in-plane stresses in Ti phase, as seen in micromechanics-based simulation results shown in Fig. 10, applied to Ti layer made brittle by titanium oxide in the FGMs described above and due to least of effect of toughening by stress-induced transformation with non $\mathrm{Y}_{2} \mathrm{O}_{3}$-containing $\mathrm{ZrO}_{2}$ in both $\mathrm{ZrO}_{2}$ phase and $\mathrm{Ti}$ (with titanium oxides) phase. In addition, transformation of $\mathrm{ZrO}_{2}$ $\left(0 \mathrm{~mol} \% \mathrm{Y}_{2} \mathrm{O}_{3}\right)$ during the fabrication process causes large strains and stresses in the materials, which can lead to crack generations and propagations and the fracture of the materials. Accordingly, $\mathrm{ZrO}_{2}\left(\begin{array}{llll}0 & \mathrm{~mol} \% & \mathrm{Y}_{2} \mathrm{O}_{3}\end{array}\right) / \mathrm{Ti} \quad \mathrm{FGMs}$ 
cannot be soundly fabricated under the present thermo-mechanical conditions by SPS. Doping of $\mathrm{Y}_{2} \mathrm{O}_{3}$ is important to prevent the fracture in the $\mathrm{ZrO}_{2} / \mathrm{Ti}$ FGMs during the fabrication processes.

Consequently, $\mathrm{ZrO}_{2}$-Ti composites are very attractive in biomedical, aerospace as well as automobile industries because of their superior biocompatibility and thermo-mechanical properties. Therefore, it is necessary to understand mechanical properties of $\mathrm{ZrO}_{2}-\mathrm{Ti}$ composites accurately based on examination of their microstructures and oxide products. From view points of hardness (compressive properties), $\mathrm{ZrO}_{2}$ is very effective to improve mechanical properties of Ti matrix, but for tensile properties, $\mathrm{ZrO}_{2}$-Ti composites exhibit much brittleness even though $\mathrm{ZrO}_{2}$-Ti composites contain very small amount of $\mathrm{ZrO}_{2}$. Such properties highly influence design processes for $\mathrm{ZrO}_{2}$-Ti composites and also $\mathrm{ZrO}_{2} / \mathrm{Ti}$ FGMs. The current study on mechanical behavior of $\mathrm{ZrO}_{2}$-Ti composites is considered to suggest guiding principals for engineering such $\mathrm{ZrO}_{2}$-Ti composites and $\mathrm{ZrO}_{2} /$ Ti FGMs.

\section{Conclusions}

Mechanical properties of $\mathrm{ZrO}_{2}-\mathrm{Ti}$ composites were investigated on hardness and tensile properties. The samples were fabricated using SPS methods. The experimental results demonstrated that a very small amount (less than 0.5 vol. \%) of $\mathrm{ZrO}_{2}$ can enhance Ti matrix in hardness and tensile strength, while an even relatively small amount (around 1 vol. \%) of $\mathrm{ZrO}_{2}$ degrade the tensile strength and ductility because of high extent of formation of titanium oxide. Data of mechanical properties of $\mathrm{ZrO}_{2}$-Ti composites can be of importance to design such composites used for biomedical and aerospace as well as automobile structures and understand thermo-mechanical behavior of $\mathrm{ZrO}_{2} / \mathrm{Ti}$ FGMs. In the FGMs, titanium oxide also formed in Ti phase according to examination on micro-Vickers and nanoindentation analysis data, which can largely influence thermo-mechanical behavior of the FGMs. A mean-field micromechanics-based analysis described that after the fabrication processes, tensile stresses are present in Ti layer in the FGMs. For $\mathrm{ZrO}_{2}\left(0 \mathrm{~mol} \% \mathrm{Y}_{2} \mathrm{O}_{3}\right) / \mathrm{Ti}$ FGMs, after fabrication processes, a lot of cracks were observed in $\mathrm{Ti}$ layer in the FGMs, which may be attributed to formation of titanium oxide in Ti layer, generation of residual stresses due to difference in thermal expansion coefficients between $\mathrm{Ti}$ and $\mathrm{ZrO}_{2}$, and a volume change of $\mathrm{ZrO}_{2}$ with no $\mathrm{Y}_{2} \mathrm{O}_{3}$ by transformation accompanied with crystal structure changes during the fabrication processes, which also leads to less transformation toughening by such $\mathrm{ZrO}_{2}$ particles.

\section{Appendix}

A mean-filed micromechanics-based model is shown here to examine the experimental results. The model used in the study is based on the work by Tsukamoto [7]. Macroscopically homogeneous composites with spherical particles are considered for a building block of an FG TBC plate. The building blocks are assumed to be subject to balanced bi-axial plane stresses. Here, the metal phase is assumed to be matrix and ceramic phase is particles, which are indicated by subscript 0 and 1 , respectively, while the inversion of the relation of matrix and particles can be easily handled in the similar way. The inelastic deformation of constituents of the composites include the creep with the strain, $\varepsilon^{\mathrm{c}}$, the plastic deformation with the strain, $\varepsilon^{\mathrm{p}}$, and the diffusional mass transport along the metal-ceramic interface with the eigen strain of the particle, $\varepsilon^{\mathrm{d}}$. The in-plane micro-stresses, $\sigma_{0}^{\text {in }}, \sigma_{1}^{\text {in }}$ and out-of-plane micro-stresses, $\sigma_{0}^{\text {out }}, \sigma_{1}^{\text {out }}$ in each phase can be written as follows $[6,7]$,

$$
\begin{array}{r}
\sigma_{0}^{\text {in }}=2\left(\beta_{0}+1 / 3 \gamma_{0}\right) \sigma+3 \mathrm{f}_{1} \beta^{*}\left(\alpha_{1}-\alpha_{0}\right) \theta \\
+2 \mathrm{f}_{1} \gamma^{*}\left\{\left(\varepsilon_{1}^{\mathrm{c}}-\varepsilon_{0}^{\mathrm{c}}\right)+\varepsilon^{\mathrm{d}}-\varepsilon^{\mathrm{p}}\right\} \\
\begin{array}{r}
\sigma_{0}^{\text {out }}=2\left(\beta_{0}-2 / 3 \gamma_{0}\right) \sigma \\
+3 \mathrm{f}_{1} \beta^{*}\left(\alpha_{1}-\alpha_{0}\right) \theta \\
-4 \mathrm{f}_{1} \gamma^{*}\left\{\left(\varepsilon_{1}^{\mathrm{c}}-\varepsilon_{0}^{\mathrm{c}}\right)+\varepsilon^{\mathrm{d}}-\varepsilon^{\mathrm{p}}\right\}
\end{array}
\end{array}
$$

for the metal matrix ((indicated by subscript 0$)$, and

$$
\begin{aligned}
\sigma_{1}^{\text {in }}=2\left(\beta_{1}+1 / 3 \gamma_{1}\right) \sigma & -3 \mathrm{f}_{0} \beta^{*}\left(\alpha_{1}-\alpha_{0}\right) \theta \\
& -2 \mathrm{f}_{0} \gamma^{*}\left\{\left(\varepsilon_{1}^{\mathrm{c}}-\varepsilon_{0}^{\mathrm{c}}\right)+\varepsilon^{\mathrm{d}}-\varepsilon^{\mathrm{p}}\right\} \\
\sigma_{1}^{\text {out }}=2\left(\beta_{1}-2 / 3 \gamma_{1}\right) \sigma & -3 \mathrm{f}_{0} \beta^{*}\left(\alpha_{1}-\alpha_{0}\right) \theta \\
+ & 4 \mathrm{f}_{0} \gamma^{*}\left\{\left(\varepsilon_{1}^{\mathrm{c}}-\varepsilon_{0}^{\mathrm{c}}\right)+\varepsilon^{\mathrm{d}}-\varepsilon^{\mathrm{p}}\right\}
\end{aligned}
$$

for the ceramic particle (indicated by subscript 1 ). Here, $\mathrm{f}_{0}$ and $f_{1}$ are the volume fraction, $\alpha_{0}$ and $\alpha_{1}$ are the coefficinet of thermal expansion, and $\sigma$ is a macro-stress due to balanced bi-axial loadings. $\beta_{0}, \beta_{1}, \gamma_{0}, \gamma_{1}, \beta^{*}$ and $\gamma^{*}$ are micromechanical constants depending on the elastic constants and volume fraction of each phase, which were given in the work by Tsukamoto [7]

In this analysis, plastic and creep deformations are supposed to obey the associated flow rule in which both deformation potentials are taken equal to the von Mises-type yield function. Plastic deformation of metal phase is assumed to be expressed by the Swift's equation:

$$
\sigma_{0}^{\mathrm{eq}}=\mathrm{a}\left(\mathrm{c}+\varepsilon^{\mathrm{p}^{\mathrm{eq}}}\right)^{\mathrm{n}_{\mathrm{p}}}
$$

where $a, c$ and $n_{p}$ are constants. $\sigma_{0}^{\mathrm{qq}}$ is the flow stress of metals. When the creep deformation of each phase is assumed to be controlled by grain-boundary diffusion (Coble creep), the constitutive equation is expressed as follows,

$$
\dot{\varepsilon}_{\text {coble }}^{\mathrm{c}}=\mathrm{C} \frac{\omega_{\mathrm{gb}} \mathrm{D}_{\mathrm{gb}} \Omega}{\mathrm{kTd}^{3}} \sigma^{\mathrm{eq}}
$$

$\mathrm{C}$ is the geometric constant $(\sim 16), \mathrm{D}_{\mathrm{gb}}$ the grain boundary diffusivity, $\omega_{\mathrm{gb}}$ the grain boundary width, $\Omega$ the volume of a diffusing atom and $\mathrm{k}$ the Boltsman's constant. The 
inelastic strain $\varepsilon^{\mathrm{d}^{\mathrm{eq}}}$ by mass transport along the interface between metal and ceramic phases is expressed as follows [7],

$$
\dot{\varepsilon}^{\mathrm{d}^{\mathrm{eq}}}=\mathrm{C}^{\mathrm{int}} \frac{\omega_{\mathrm{int}} \mathrm{D}_{\text {int }} \Omega}{\mathrm{kTd}_{\mathrm{p}}^{3}} \sigma_{1}^{\mathrm{eq}}
$$

$\mathrm{C}^{\text {int }}$ is the material constant derived from micromechanical considerations, $\omega_{\text {int }}$ the interface width for diffusion, $\mathrm{D}_{\text {int }}$ the interfacial diffusivity and $\Omega$ the volume of diffusing atom. Therefore, when considering the composites under plane-stress conditions, the constitutive equations can be derived as,

$$
\begin{aligned}
\dot{\sigma}(z, t)= & \left\{S^{\mathrm{e}}(\mathrm{z})+\mathrm{S}^{\mathrm{p}}(\mathrm{z}, \mathrm{t})\right\}^{-1} \\
& \left\{\dot{\varepsilon}(\mathrm{z}, \mathrm{t})-\alpha(\mathrm{z}) \dot{\theta}(\mathrm{z}, \mathrm{t})-\varepsilon^{\mathrm{p}(\mathrm{cd})}(\mathrm{z}, \mathrm{t})-\varepsilon^{\mathrm{c}-\mathrm{d}}(\mathrm{z}, \mathrm{t})\right\}
\end{aligned}
$$

$\dot{\sigma}(\mathrm{z}, \mathrm{t})$ is the plane stress rate, $\dot{\varepsilon}(\mathrm{z}, \mathrm{t})$ the plane strain rate, $S^{\mathrm{e}}(\mathrm{z})$ the overall plane-stress elastic compliance, $S^{\mathrm{p}}(\mathrm{z}, \mathrm{t})$ the overall plane-stress plastic compliance, $\alpha(z)$ the overall in-plane thermal expansion coefficient, $\dot{\varepsilon}^{\mathrm{p}(\mathrm{cd})}(\mathrm{z}, \mathrm{t})$ the overall plastic strain rate due to the difference between creep abilities of each phase and interfacial diffusion, and $\dot{\varepsilon}^{\mathrm{c}-\mathrm{d}}(\mathrm{z}, \mathrm{t})$ the overall creep strain rate. The details for mathematical expressions of these functions are given in the work by Tsukamoto [7]. $\dot{\sigma}(\mathrm{z}, \mathrm{t})$ given in Eq. (A8) can be incorporated with the lamination theory.

The material property data of both $\mathrm{Ti}$ and $\mathrm{ZrO}_{2}$ used in the calculation are given in Table 1 . The sample size is the same as that of real samples, for which the thickness is $9 \mathrm{~mm}$ (including $3 \mathrm{~mm}$ thickness for the FGM part and $6 \mathrm{~mm}$ thickness for the substrate part). The thermo-mechanical boundary conditions are assumed as follows: at the beginning, the samples being sintered is compacted in dice (fully constraint in both in-plane and out-of-plane deformations) at $1400{ }^{\circ} \mathrm{C}$. Under this condition, there is no stress in the materials. Then temperature goes down to room temperature $\left(25^{\circ} \mathrm{C}\right)$ under the mechanical boundary conditions of fully constraint deformation. After that, at R.T., all the mechanical constraints are relieved (mechanical constraint is free.).

Table 1. Material property data of $\mathrm{Ti}$ and $\mathrm{ZrO}_{2}$ used in the calculation.

\begin{tabular}{lll}
\hline & Ti & $\mathbf{Z r O}_{2}$ \\
\hline Young's modulus $/ \mathrm{GPa}$ & 116 & 200 \\
Poisson's ratio & 0.32 & 0.3 \\
$\mathrm{CTE} / 10^{-6} \mathrm{~K}^{-1}$ & 8.6 & 10.0 \\
Thermal conductivity/ $\mathrm{Wm}^{-1} \mathrm{~K}^{-1}$ & 21.9 & 3.0 \\
Specific heat $/ \mathrm{Jkg}^{-1} \mathrm{~K}^{-1}$ & 520 & 3000 \\
Density / $\mathrm{kgm}^{-3}$ & 4506 & 5990 \\
[Coble creep parameters] & & \\
$\mathrm{D}_{\text {gb0 }}$ (pre-exp. Term) $\times \mathrm{W}_{\mathrm{gb}} / \mathrm{m}^{3} \mathrm{~s}^{-1}$ & $1.9 \times 10^{-7}$ & $0.29 \times 10^{-6}$ \\
Activation energy / Jmol & & $5.7 \times 10^{5}$ \\
Atomic volume $/ \mathrm{m}^{3}$ & $1.53 \times 10^{5}$ & $4.66 \times 10^{-29}$ \\
Grain size / m & $1.15 \times 10^{-29}$ & $10.0 \times 10^{-6}$ \\
[Plasticity parameter] & $10.0 \times 10^{-6}$ & \\
a/ MPa & & - \\
$\mathrm{c}$ & 600 & - \\
$\mathrm{n}_{\mathrm{p}}$ & 0.3 & - \\
\hline
\end{tabular}

\section{References}

[1] A.W. Nugroho, G. Leadbeater, I.J. Davies, "Processing of a porous titanium alloy from elemental powders using a solid state isothermal foaming technique," J. Mater. Sci Mater Med, 2010, vol. 21, pp. 3103-3107.

[2] T. Lidong, L. Wenchao. "Residual stress analysis of $\mathrm{Ti}-\mathrm{ZrO}_{2}$ thermal barrier graded materials," Mater Design, 2002, vol.23, pp. 627-632.

[3] R.C. Gravie, R.H. Hannink, R.T. Pascoe, "Ceramic steels," Nature, 1975, vol. 258, pp.704-730.

[4] P.M. Kelly, L.R.F. Rose, "The martensitic transformationin ceramics- its role in transformation toughening," Prog Mater Sci, 2002, vol. 47, pp. 463-557.

[5] H. Tsukamoto, "Micromechanical modeling of transformation toughening in multi-phase composites enriched with zirconia particles," Comp Mater Sci, 2010, vol. 48 , pp. $724-729$.

[6] H. Tsukamoto, "Design against fracture of functionally graded thermal barrier coatings using transformation toughening," Mater Sci Eng A, 2010, vol. 527, pp. 3217-3226.

[7] H.Tsukamoto, "Analytical method of inelastic thermal stresses in a functionally graded material plate by a combination of micro- and macromechanical approaches," Compos Part B-Eng, 2003, vol. 34, pp. 561-568.

[8] K. Kokini, J. DeJonge, S. Rangaraj, B. Beardsley, "Thermal shock of functionally graded thermal barrier coatings with similar thermal resistance," Surf Coat Tech, 2002, vol. 154, pp. 223-231.

[9] Z. Han, B. Xu, H. Wang, S. Zhou, "A comparison of thermal shock behavior between currently plasma spray and supersonic plasma spray $\mathrm{CeO}_{2}-\mathrm{Y}_{2} \mathrm{O}_{3}-\mathrm{ZrO}_{2}$ graded thermal barrier coatings," Surf Coat Tech, 2007, vol. 201, pp. 5253-5256.

[10] L.D. Teng, F.M. Wang, W.C. Li, "Thermodynamics and microstructure of $\mathrm{Ti}-\mathrm{ZrO}_{2}$ metal-ceramic functionally graded materials," Mater Sci Eng A, 2000, vol. 293, pp. 130-136.

[11] L.D. Teng, W.C. Li, F. M. Wang, "Effect of Ti content on the martensitic transformation in zirconia for $\mathrm{Ti}_{-} \mathrm{ZrO}_{2}$ composites," J Alloy Compd, 2001, vol. 319, pp. 228-232.

[12] K.L. Lin, C.C. Lin, "Reaction between titanium and zirconia powders during sintering at $1500^{\circ} \mathrm{C}$," J Am Ceram Soc, 2007, vol. $90,2220-2225$.

[13] T.A. Schaedler, O. Fabrichnaya, C.G. Levi, "Phase equilibria in the $\mathrm{TiO}_{2}-\mathrm{YO}_{1.5}-\mathrm{ZrO}_{2}$," J Euro Ceram Soc, 2008, vol. 28, pp. 2509-2520.

[14] B.C. Weber, H.J. Garrett, F.A. Mauer, M.A. Schwartz, "Observations on the stabilization of zirconia," J Am Ceram Soc, 1956, vol. 39, pp. 197-207.

[15] A. Arias, "Thermal shock resistance of zirconia with 15 mol \%Titanium," J Am Ceram Soc, 1966, vol. 49, pp. 334-338. 
[16] M. Omori, "Sintering, consolidation, reaction and crystal growth by the spark plasma system (SPS)," Mater Sci Eng A, 2000, vol. 287, pp. 183-188.
[17] H. Tsukamoto, T. Kunimine, M. Yamada, H. Sato, Y.Watanabe, "Microstructure and mechanical properties of Ti- $\mathrm{ZrO}_{2}$ composites fabricated by spark plasma sintering," Key Eng Mat, 2012, vol. 520, pp. 269-275. 